\title{
ИЗУЧЕНИЕ ПРОБЛЕМ МЫШЛЕНИЯ НА КАФЕДРЕ ОБЩЕЙ ПСИХОЛОГИИ И ИСТОРИИ ПСИХОЛОГИИ МОСКОВСКОГО ГУМАНИТАРНОГО УНИВЕРСИТЕТА
}

\author{
И. Р. Федоркова \\ Московский гуманитарный университет
}

\begin{abstract}
Аннотация: В статье представлены и обсуждаются результаты психологических исследований, выполненных преподавателями и обучающимися кафедры общей психологии и истории психологии Московского гуманитарного университета. Особое внимание уделено исследованиям стилей мышления и рассмотрению мышления на макро- и мезо уровнях.
\end{abstract}

Ключевые слова: мышление; стиль мышления; тип мышления; личность; восточный тип мышления; западный тип мышления; обзор; Московский гуманитарный университет

\section{STUDIES INTO THE THINKING ISSUE AT THE DEPARTMENT OF GENERAL PSYCHOLOGY AND THE HISTORY OF PSYCHOLOGY OF MOSCOW UNIVERSITY FOR THE HUMANITIES}

\author{
I. R. Fedorkova \\ Moscow University for the Humanities
}

\begin{abstract}
The paper presents and discusses the results of the psychological studies that were conducted by the teachers and students at the Department of General Psychology and the History of Psychology of Moscow University for the Humanities. Special attention is paid to the studies of thinking styles and to the consideration of thinking at the macroand meso levels.
\end{abstract}

Keywords: thinking; thinking style; thinking type; personality; eastern thinking type; western thinking type; review; Moscow University for the Humanities

На факультете психологии Московского гуманитарного университета в рамках курса «Общей психологии» преподается дисциплина «Психология мышления». Один из важных разделов курса нацелен на рассмотрение конкретных механизмов осуществления мышления и в этом плане необходимо подробно проанализировать феномены объекта и субъекта мышления, так как именно в этой области в большей степени сосредоточен прикладной компонент знаний, получаемых в ходе изучения курса. Под мышлением в психологии понимают процесс постановки и решения задач. Таким образом, объектом мышления является за- 
дача, которая запускает процесс мышления и контролирует его ход, а в качестве субъекта выступает сам мыслящий индивид.

Несмотря на важность всех изучаемых феноменов психологии мышления, центральным все же представляется характеристика самого субъекта мышления - человека мыслящего - и его индивидуальных характеристик, влияющих на процесс эффективного решения задачи. Среди таких значимых компонентов выделяются: мотивация; уровень развития интеллекта и креативности; сумма полученных знаний, умений и навыков; индивидуальная степень выраженности видов и свойств мышления, а также типы и стили мышления.

Типы и стили мышления могут рассматриваться как на глобальном, общекультурном уровне (макроуровень), так и на уровне индивидуальных различий (мезо- и микроуровни).

На макроуровне условно можно выделить два основных типа мышления: восточное и западное. Понимание сущности данных феноменов имеет высокий уровень прикладного значения: во-первых, для понимания правомерности использования психологического инструментария, подготовленного для диагностики умственного развития в разных культурах (восточной и западной), вовторых, для осуществления эффективного взаимодействия с представителями разных культур, в том числе при совместном решении некоторых задач.

В основу различий западного и восточного типов мышления положены разные законы и принципы, на которое опираются эти психические явления (Психология и культура, 2003). Западное мышление опирается на законы, выявленные еще древнегреческими философами, это - закон тождества, закон исключенного третьего и закон непротиворечия. Данные законы констатируют, что любая сущность тождественна сама себе; любое суждение либо истинно, либо ложно; никакое высказывание не может быть одновременно истинным и ложным. Принципы, на которое опирается восточное мышление, противоположны по своей сути и находят свое воплощение в работах восточных мыслителей. Это - принцип изменения, принцип противоречия и принцип холизма. Принцип изменения гласит, что нет ничего, что тождественно само себе, поскольку реальность изменчива и неустойчива, таким образом, одна и та же сущность сейчас и через некоторый промежуток времени будет отличаться. Принцип противоречия вытекает из вышесказанного и констатирует, что постоянные изменения и противоречия приводят к тому, что старое и новое, хорошее и плохое сосуществуют в одно и то же время в одном и том же объекте. В свою очередь, принцип холизма гласит: поскольку изменения и противоречия постоянны, в жизни человека и его характере ничто не является изолированным от другого, все взаимосвязано и попытки выделить отдельные составляющие единого целого могут ввести в заблуждение. Эти принципы лежат в основе формирования Я-концепции, которая в западном варианте выглядит как «независимое Я», а в восточной — «взаимозависимое Я».

Описанные феномены определяют различия в протекании отдельных механизмов мышления.

Например, рассматривая ситуацию конфликта, противоречий представители западной культуры традиционно проводят логический анализ, в ходе которого пытаются отвергнуть одно утверждение в пользу другого, а представители 
восточного типа мышления стараются принять оба утверждения, обнаружив в каждом из них достоинства и недостатки (поиск «золотой середины»). Данный феномен выявлен в ходе проведения большого количества экспериментов, предполагающих решение проблемных ситуаций. В одном из таких экспериментов на суд представителей западной и восточной аудиторий была представлена конфликтная ситуация между матерью и дочерью. Представители западной культуры принимали либо позицию дочери, объясняя при этом, в чем она не права, либо становились на сторону матери, объясняя, в чем не согласны с дочерью. Представители восточной аудитории пытались уладить конфликт, объяснив почему, по их мнению, неправы обе стороны, предлагая найти компромиссное решение.

Принцип атрибуции - установления причинно-следственных связей используется людьми с доминированием западного и восточного типов мышления также по-разному. Представители западной культуры при выявлении причинноследственных связей будут опираться на внутренние свойства объекта и будут склонны приписывать причины разных событий действиям отдельных личностей. В то время как обладатели восточного типа мышления при рассмотрении подобных вопросов будут ориентироваться на поле и основное внимание уделять обстоятельствам и действиям социальных групп. Проиллюстрируем описываемый феномен на конкретных примерах.

Объясняя причины преступности, носители западного типа мышления размышляли о наличии у убийц психических расстройств или негативных склонностей, в то время как представители восточной культуры обращали внимание на социальные факторы и объясняли причины преступлений особенностями воспитания, сформированными во взаимодействии с другими людьми. В другом эксперименте в каждой группе (западной и восточной) демонстрировался видеоролик, в котором одна рыбка плывет чуть впереди всей стаи. Испытуемым предлагалось описать происходящее на экране. Представители западной культуры сказали, что рыбка является лидером и куда-то ведет за собой группу, а представители восточной культуры заявили, что стая почему-то догоняет эту рыбку.

Традиционную классификацию объектов (данный прием является центральным в диагностике мышления на разных возрастных этапах) представители западной и восточной культур также будут осуществлять по-разному. Первые будут делать свои выводы на основе формальных свойств, поддающихся выделению, вторые - на основе контекста и функциональной принадлежности объекта. Например, при классификации животных дети - представители западной культуры использовали такие критерии как «размер, степень свирепости», а представители восточной культуры - «среда обитания, корм, особенности охоты». В другом эксперименте детям - представителям западной и восточной культур предлагалось разделить три карточки с изображение мужчины, женщины и ребенка на две группы. Носители западного типа мышления в одну группу поместили мужчину и женщину, в другую - ребенка, назвав выделенные группы - «взрослые» и «ребенок», а носители восточного типа мышления в одну группу поместили женщину и ребенка, а во вторую - мужчину, объяснив это так: «мама заботится о ребенке», а «папа обеспечивает семью, работает».

Известный американский психолог М. Коул в 70-х годах XX века проводил 
кросскультурные исследования в Западной Африке (Коул, 1997). В качестве испытуемых выступал народ кпелле. Цель проводимого исследования была прикладная - увеличить степень образованности данного народа, построив эффективную систему его обучения. Первоначально М. Коул использовал классические методики для определения умственных способностей кпелле и пришел к выводу: они «тупые». Но когда его виртуозно обсчитали в автобусе и на рынке, понял они не «тупые». Надо искать иные способы диагностики их умственных способностей. Коул предположил, что центральным является характер деятельности данного народа и тестовые задания нужно построить, исходя из этого. Поскольку народ кпелле выращивал рис и продавал его на рынке в сосудах разных объемов, Коул все те задачи, которые давал первоначально испытуемым в абстрактной форме, составил так, что основными элементами задач являлись привычные для народа категории (сосуды с рисом). Результат превзошел все его ожидания, задания были выполнены блестяще. Ученый сделал вывод о том, что умственные способности каждого народа нужно оценивать с точки зрения социально-исторического контекста, в чем его идея согласуется с теорией Л. С. Выготского (Выготский, 1984; Выготский, Лурия,). Представляется не случайным также и тот факт, что М. Коул посвятил свою книгу А. Р. Лурии - одному из первых сотрудников лаборатории Л. С. Выготского, проводившему одно из первых кросскультурных исследований в Узбекистане в 30-х гг. ХХ века (Лурия, 1974).

Исследования М. Коула дали нам дополнительные знания о восточном и западном типе мышления. Он решил предоставить своим испытуемым для выполнения классический тест «Четвертый лишний», но с измененной инструкцией: ответить так, как ответил бы на вопрос, по их мнению, умный человек и глупый человек. Например, в качестве стимульного материала испытуемым предоставлялось 4 слова: «апельсин», «банан», «яблоко» и «нож». Кпелле отвечали приблизительно так: «Глупый человек уберет нож и скажет, что оставшиеся предметы - фрукты; а умный человек нож оставит, а иначе чем он будет резать фрукты». Данные результаты совершенно неожиданно показали, что восточные люди понимают законы западной логики, но для них они не являются верными. Таким образом, чтобы делать выводы о продуктивности мышления того или иного народа нужно обязательно учитывать культурно-исторический контекст и сформированный в его рамках тип мышления.

После прочитанной лекции по данному вопросу, мы часто задаем студентам вопрос: «Как вы думаете, какой тип мышления: восточный или западный в большей степени характерен для нашего народа?» Подавляющее большинство студентов называли восточный тип мышления как характерный для нашего народа, но некоторые студенты считали, что ведущим типом мышления для наших соотечественников является - западный. Вероятно, во многом, данные ответы студентов обусловлены феноменом проекции, а также данные ответы свидетельствуют о том, что и западный, и восточный стили мышления проявляются в выборке наших соотечественников. Интересным примером тому служит высказывание одной из студенток - обладательниц выраженного восточного тип мышления: «Теперь я поняла, почему никак не могу понять В.» (сама В. в процессе опроса сказала, что западный стиль является ведущим для отечественной выборки). 
Вышеописанные феномены касаются глобальной характеристики типов мышления и проведение подобных исследований практически невозможно в условиях обучения в вузе. Но изучение индивидуальных особенностей мышления на микроуровне, на уровне стилей мышления, вполне возможно и весьма интересно для начинающих специалистов-психологов.

Стили мышления - это индивидуально-своеобразные способы постановки и решения задач. Разные люди решают одни и те же задачи по-разному: задают себе разные вопросы, методически по-разному организуют процесс их решения. Некоторые из них, например, анализируют небольшие объемы однородной непротиворечивой информации (аналитики), в то время как другие - одновременно обрабатывают разнородную, разноуровневую информацию, центрируясь, в первую очередь, на поиске противоречий (синтетики).

Изучение проблемы стилей мышления учащимися под руководством педагогов кафедры общей психологии и истории психологии Московского гуманитарного университета проводились на протяжении ряда лет (Авдеева, 2009; Костикова, 2009; Подторжнова, 2010; Аракелян, 2015; Тащи, 2015). Проведенные исследования были нацелены на выявление взаимосвязей стилей мышления с разными индивидно-личностными и социально-психологическими характеристиками: полом, возрастом, темпераментом, личностными свойствами, академическим интеллектом и социальным интеллектам, способами выхода из конфликта, копинг-стратегиями, способами преодоления фрустрации и др.

Теоретико-методической основой проведенных исследований явилась концепция А. Ф. Харрисона и Р. М. Брамсона, которые выделили и охарактеризовали пять интеллектуальных стилей: синтетический, идеалистический, прагматический, аналитический и реалистический (Харрисон, Брамсон, 1998). Данную концепцию в рамках отечественной психологии популяризируют А. А. Алексеев и Л. А. Громова (Алексеев, Громова, 1993).

Эмпирических исследований, направленных на изучение стилей мышления, в научной психологической литературе не так много. Нам удалось найти две работы, посвященные изучению возрастных и гендерных особенностей стиля мышления студентов (Молохина, 2010) и особенностей профессиональной готовности к психодиагностической деятельности студентов-психологов с разными стилями мышления (Ачина, 2013). Таким образом, исследования, проведенные на кафедре общей психологии и истории психологии МосГУ, характеризуются несомненной научной новизной.

Остановимся на изложении наиболее интересных результатов этих исследований.

Все проведенные нами и под нашим руководством исследования показали, что стили мышления не связаны с такой индивидной характеристикой как «пол», следовательно, и мужчины, и женщины в равной степени предпочитают и отвергают разные стили мышления. Данный вывод можно считать надежным, так как он подтвержден на большой выборке испытуемых разными исследователями.

В качестве испытуемых в большинстве проведенных нами исследований выступали студенты разных вузов, представители разных специальностей: гуманитарных и естественнонаучных. В целом выявлено, что реалистический стиль 
мышления предпочитают студенты гуманитарных специальностей: психология, реклама, а аналитический стиль мышления в большей степени используется студентами естественнонаучных и технических специальностей: экономика, физика, математика. синтетический стиль чаще всего отвергается студентами всех видов специальностей, а идеалистический и прагматический стили не являются предпочитаемыми или отвергаемыми, и в равной степени используют и студентами - гуманитариями, и студентами естественнонаучных специальностей.

Несколько иная ситуация наблюдается в группе старших подростков. Они отвергают популярный у студентов реалистический стиль мышления наряду с традиционно отвергаемым синтетическим стилем, предпочитая использовать аналитический и прагматический стили (Аракелян, 2015).

В исследовании О. Ю. Подторжновой (Подторжнова, 2010) в качестве испытуемых выступали представители разных возрастных групп, в результате чего удалось установить, что идеалистический и прагматический стили мышления в большей степени используются более молодыми представителями выборки, а представители старшего поколения предпочитают использовать синтетический стиль мышления.

По мнению В. Н. Дружинина (Дружинин, 1999) индивидуальные стили мышления начинают формироваться ближе к подростковому возрасту и само понятие «стиля мышления» предполагает наличие достаточно высокого уровня интеллекта, на основе которого возможно построение своеобразного мыслительного стиля. Пилотажный анализ предпочитаемых стилей мышления по возрастам позволил предположить, что динамика предпочтения такова: аналитический-реалистический-синтетический. Таким образом, синтетический стиль мышления условно может быть назван «стилем мудрости».

Синтетический стиль, по мнению Харрисона и Брамсона (Харрисон, Брамсон, 1998) - самый редкий из всех обозначенных стилей. Данный вывод нашел подтверждение и в наших исследованиях. Это сугубо теоретический стиль, направленный на постоянное проведение мыслительного эксперимента. «Синтезаторы» не особенно интересуются компромиссом, согласием по поводу «наилучшего» решения проблемы, они заняты поиском перспективы, могущей привести к «наиболее подходящему» решению, сочетающему в себе взгляды, которые кажутся противоречивыми. В отличие от обладателей других стилей мышления, «Синтезаторы» твердо признают лишь один «факт»: всегда существовали, существуют и будут существовать среди людей расхождения во мнениях по фактам.

«Синтезаторы» склонны видеть мир постоянно меняющимся и одобряют такое видение мира другими людьми. Их не страшит неопределенность. Они гордятся своим «творчеством», резкостью суждений и - часто втайне - своей сообразительностью. Согласно современной терминологии, принятой в психологии, таких людей мы можем назвать креативными.

Несмотря на то, что синтетический стиль являлся отвергаемым во всех выборках наших испытуемых, он в большей степени поддается описанию с точки зрения разных психологических и социально-психологических характеристик, в связи с установлением относительно большого количества связей этого стиля с изучаемыми феноменами. По обобщенным результатам наших исследований 
можно составить описание психологического портрета индивидов, предпочитающих использовать данный стиль мышления.

«Синтезаторы», обладая сильной, уравновешенной и подвижной нервной системой, являются людьми в большей степени застенчивыми, уступчивыми, подчиненными с развитым чувством долга и ответственности, стремятся к соблюдению общепринятых моральных норм и правил. У них выше, чем у представителей других стилей, выражен невербальный интеллект, развиты математические способности и пространственное мышление (комбинаторные способности при создании целостного образа на основе имеющихся частей) (Подторжнова, 2010). Они являются обладателями высокого уровня развития социального интеллекта (наряду с «идеалистами» и «прагматиками»); им особенно легко удается предвосхищать последствия поведения людей, на основе анализа их чувств и намерений, и успешно приспосабливаться к изменяющейся ситуации общения (Авдеева, 2009). Несмотря на то, что «синтезаторы» центрируются при решении задач на поиске противоречий, для преодоления сложных жизненных ситуаций, они предпочитают использовать в качестве копинг-стратегии положительную переоценку, т. е. усиленно создают положительный образ и значение проблемы, фокусируясь при этом на собственном личностном росте (Костикова, 2009). Представители данного стиля мышления редко склонны винить себя за возникшую конфликтную ситуацию, не фиксируются на ней, не занимаются самообвинением и вместе с тем не склонны требовать разрешения фрустрирующей ситуации со стороны других лиц. В затруднительных ситуациях они хорошо способны замечать расхождения и готовы сами предложить свою новую и оригинальную идею, не прибегая к помощи посторонних лиц (Тащи, 2015). При этом, само по себе быстрое разрешение конфликтной ситуации их не так интересует. С одной стороны, это позволяет «синтезаторам» хорошо справляться с неоднозначными ситуациями, потенциально конфликтогенными, тем самым создавая атмосферу дебатов и творчества, с другой стороны, представители данного стиля склонны избыточно теоретизировать ситуацию, смотреть на нее слишком абстрактно, и в результате чего могут оказаться безответственными, не прилагая попыток к ее скорейшему разрешению. Для подростков с доминирующим синтетическим стилем мышления характерным является высокий уровень социальной и когнитивной рефлексивности (Аракелян, 2015).

Аналитический стиль - следующий теоретико-ориентированный стиль мышления, по нашим исследованиям - один из доминирующих стилей и среди групп старшеклассников, и среди студентов вузов. Описание этого стиля, данного Харрисоном и Брамсоном таково: «аналитики» подходят к решению проблем осторожно, логично и методично, обращая внимание на детали. Тщательно все планируя, они собирают как можно больше информации перед тем, как принять решение. «Аналитика», как никакого приверженца иных стилей мышления, больше всего интересует «теория». «Аналитики» стремятся иметь «теорию» для всего на свете. Они анализируют и выносят суждения в самых общих рамках, что помогает объяснять ситуацию и приходить к выводу. Представитель это стиля мышления видит мир логичным, рациональным, упорядоченным (или управляемым) и пред- 
сказуемым. А в том случае, когда из-за существующих обстоятельств такая картина мира невозможна, где-то глубоко в системе ценностей «аналитика», по крайней мере, остается убеждение, что мир должен быть таким. Мыслительный процесс «аналитика» носит предписывающий характер. Встретившись с проблемой, он станет искать метод, формулу, процедуру или систему, которая поможет ее решить. В связи с интересом к формуле или методу «аналитику» нравится поиск «единственного лучшего пути» решения проблемы. Он гордится своей компетентностью, под которой понимается знание всех граней ситуации, какой бы она ни была.

Достаточно часто в работах разных авторов можно обнаружить закономерное противопоставление «аналитиков» и «синтезаторов». Обоснованием этому служит противоположность мыслительных операций, положенных в основу этих стилей. Данные мыслительные операции и их функции наиболее подробно и развернуто описаны в работах классика отечественной психологии С. Л. Рубинштейна (Рубинштейн, 1998). Под анализом он понимает мысленное расчленение предмета, явления, ситуации и выявление составляющих его элементов, частей, сторон. Синтез, в свою очередь, раскрывает более или менее существенные связи и отношения выделенных анализом элементов.

В основе различия двух когнитивных стилей - узкий диапазон эквивалентности (аналитический) и широкий диапазон эквивалентности (синтетический) также лежит функциональная противоположность анализа и синтеза (Дружинин, 1999; Холодная, 2004).

В рамках наших исследований практически во всех группах был отмечен феномен существования отрицательной корреляционной связи между синтетическим и аналитическим стилями мышления, что в очередной раз доказывает противоположность данных феноменов и подтверждает адекватность использованного методического инструментария.

В отличие от ситуации с синтетическим стилем, представителей аналитического стиля мышления нам трудно охарактеризовать дополнительно, так как выявлено очень мало корреляционных связей данного стиля с изучаемыми нами явлениями. Таким образом, индивиды, использующие аналитический стиль мышления не имеют четко выраженного психологического портрета. Можно отметить только две характерные черты представителей данного стиля: высокий уровень когнитивной рефлексивности (Аракелян, 2015) и особый способ выхода из фрустрирующей ситуации: они стремятся быстро и эффективно разрешить проблему преимущественно через других лиц, при этом, не концентрируясь на препятствии, вызвавшем фрустрацию субъекта (Тащи, 2015). Столкнувшись с затруднительной ситуацией, «аналитики» подходят к ее разрешению осторожно, логично и методично, тщательно все планируя и собирая как можно больше информации перед тем, как принять решение. Они предпочитают сосредоточиться на объективных данных, на самой процедуре выхода из фрустрирующей ситуации и наилучшем методе для того, чтобы это сделать. И как показали результаты - лучшим способом они видят разрешение ситуации посредством привлечения к ней других людей. Минусом здесь может являться тот факт, что слишком увлекаясь планированием и анализом, «аналитики» могут быть негибкими и проявлять излишнюю осторожность. 
Идеалистический стиль, по мнению Харрисона и Брамсона, является наиболее популярным из пяти существующих стилей (наши исследования этого не подтверждают: идеалистический стиль в целом по выборкам чаще либо умеренно предпочитается, либо умеренно отвергается). Основная стратегия «идеалиста» - ассоциирующее мышление. Они склонны к интуитивным, глобальным оценкам и не утруждают себя детальным анализом проблем с опорой на полное множество фактов и формальную логику. Для мыслительных процессов «идеалистов» характерна восприимчивость. Они приветствуют разнообразие мнений, широкий взгляд на вещи и множество альтернатив. «Куда мы идем и зачем?»классический вопрос «идеалистов». Они сходны с «синтезаторами» в том, что не склонны концентрироваться на точных цифрах и сухих фактах. Различие же между ними - в разных подходах к разрешению противоречий: «идеалисты» склонны верить, что разногласия и споры всегда можно уладить и что люди способны договориться о чем угодно, как только придут к согласию относительно целей. Отсюда ясно, что «идеалисты» не ценят конфликт и не получают от него удовольствия, он кажется им непродуктивным, следовательно, абсолютно ненужным (данные выводы авторов методики подтверждены нашими исследованиями). Когда дело доходит до решения проблем, «идеалисты» лучше всего подходят для ситуаций, в которых важны ценности, суждения, чувства и эмоции, субъективные факторы конкретных обстоятельств.

По результатам наших исследований, дополнительные характеристики для индивидов, предпочитающих использовать идеалистический стиль мышления таковы. Для них характерна: общительность, готовность к сотрудничеству, активность в устранении конфликтов в группе, легкость в установлении контактов; им присущ повышенный интерес к «качеству жиз ᄀни», к благу отдельных людей и общества в целом. Они ориентированы на людей (Подторжнова, 2010).

Индивидам с доминированием идеалистического стиля мышления присущи высокий уровень развития словесно-логического мышления, способность к обобщению вербальной информации, высокий уровень потенциальных интеллектуальных возможностей (Подторжнова, 2010).

Таким образом, «синтезаторы» и «идеалисты» по-разному проявляют свои ярко выраженные комбинаторные способности; первые эффективны в работе с невербальным материалом, вторые - с вербальным. «Синтезаторам» легче обобщать схемы, геометрические, графические образы, а «идеалистам» - тексты, резюмируя основные мысли письменных сообщений.

Для «идеалистов» характерен высокий уровень развития социального интеллекта; они способны правильно понимать и предвидеть последствия ситуации, обращая внимание на чувства и намерения людей, но испытывают сложности при анализе ситуаций с неполными данными (Авдеева, 2009).

Исследование М. П. Костиковой (Костикова, 2009) показало, что «идеалисты» склонны к использованию механизма избегания при возникновении конфликтной ситуации. Данный вывод дополняется результатами, полученными в исследовании К. В. Тащи (Тащи, 2015), которая выявила, что для «идеалистов» характерно стремление отрицать значимость или неблагоприятность препятствия, обстоятельств фрустрации, вместо этого все препятствия со стороны «иде- 
алистов» рассматриваются примиряющим образом. Поскольку «идеалист» 一 это человек, настроенный на поиск гармонии и согласия между людьми, который внимателен к чужим проблемам и при этом тактичен и часто неуверен в себе, то становится понятным, что от него и не следует ожидать прямого выхода на конфликт и обвинения в нем кого бы то ни было. Несколько консервативные во взглядах и привычках «идеалисты», могут иногда и затягивать решение проблем, колеблясь в выборе или стараясь найти лучший вариант для их реализации с целью не задеть и не обидеть любую из сторон конфликта. При этом сами они будут болезненно реагировать в конфликте на ссоры, цинизм, безнравственность, эгоизм и черствость.

Следующие два стиля мышления мы с уверенностью можем назвать практико-ориентированными.

Реалистический стиль мышления согласно данным наших исследований предпочитается студентами гуманитарных специальностей и отвергается старшими подростками. Можно предположить, что такие результаты связаны с доминированием теоретизирующего мышления у подростков (Психология развития ... , 2002), а потребность в практико-ориентированном стиле появляется несколько позже.

Харрисон и Брамсон следующим образом дают характеристику данному стилю. «Реалисты» являются эмпириками. Для них реально то, что можно потрогать, понюхать, почувствовать, увидеть, услышать, лично наблюдать или испытать то есть получить факты. В этом отношении «реалист» противоположен «синтезатору», который допускает большую важность заключений, а не воспринимаемых «фактов». Представители этого стиля мышления твердо убеждены, что два умных человека, снабженные должным образом всеми органами чувств, придут к согласию по поводу фактов незамедлительно. Однако «реалисты» не могут не видеть, что люди далеко не всегда соглашаются друг с другом, и это очень их беспокоит. Мыслительный процесс «реалиста» имеет корректирующее качество, они ориентированы на достижение конкретных результатов и стремятся делать все прочно, долговечно и надежно. «Реалист» ближе всех стоит к «аналитикам». Оба эти стиля конкретны, ориентированы на цели и факты, заинтересованы в упорядоченном и практичном результате. Однако, в отличие от «аналитика», «реалист» быстро теряет терпение, он желает достижения результата при помощи подручных фактов, без сбора дополнительной информации. Для «реалиста» характерна индукция и эмпиризм, а для «аналитика» - дедукция и анализ.

Общее между «реалистами» и «синтезаторами» - потребность контролировать ситуацию. Первые испытывают потребность контролировать ресурсы, людей и результаты, а вторые - потребность контролировать процесс. И те, и другие склонны приходить в раздражение от чрезмерно детального анализа и затянувшейся дискуссии.

Психологический профиль, полученный по итогам наших исследований, свидетельствует о том, что индивид, предпочитающий реалистический стиль мышления в своем поведении склонен к непостоянству, подвержен влиянию чувств, случая и обстоятельств, он гибок по отношению к социальным нормам, может быть склонен к асоциальному поведению. 
Нервная система «реалистов» при этом отличается инертностью, ригидностью, они медленно перестраиваются при столкновении с новыми раздражителями, не способны быстро реагировать на изменившуюся ситуацию, требующую быстрых и адекватных реакций. Парадоксальность полученных результатов в отношении «реалистов» заключается в том, что они как представители практически ориентированного стиля мышления, призванного решать задачи «здесь и сейчас», ориентирующиеся на конкретный результат, вместе с тем обладают ригидностью нервных процессов, сложностью их перестройки и, в конечном итоге, скорее всего, предпочтут действовать в одном выбранном для себя направлении на основе имеющихся стандартных способов решения. Также у «реалиста» прослеживается тенденция к отрицательной корреляционной связи со всеми остальными темпераментальными свойствами. Таким образом, нервная система практиков - «реалистов» оказывается слабее, чем нервная система теоретиков«синтезаторов» (Подторжнова, 2010).

При возникновении затруднительной ситуации для «реалистов» является характерным надеяться на благополучное разрешение проблем со временем, что часто сопровождают уступчивость и конформность в поведении. Представители этого стиля не обостряют конфликт, однако заинтересованы в решении самой проблемы, и только в случае, если дела идут не так как нужно, вносят поправки и твердо придерживаются намеченного курса. При этом «реалисту» чужды развернутые, последовательные суждения, поиск наилучшего варианта решения, столь характерные для аналитика; он стремится к тому, чтобы любое дело заканчивалось по возможности хорошо, а при прогнозе исхода ситуации опирается на конкретные имеющиеся факты (Костикова, 2009).

У подростков-«реалистов» низкий уровень самопринятия (Аракелян, 2015). Возможно, именно этим фактом и объясняется доминирование данного стиля мышления в студенческой аудитории студентов-психологов. Низкий уровень самопринятия, критичное отношение к себе и желание преодолеть эту проблему приводят старшеклассников в профессию психолога.

Прагматический стиль по результатам наших исследований наряду с реалистическим является одним из предпочитаемых стилей. Сущностная характеристика, данная этому стилю Харрисоном и Брамсоном, такова: основная стратегия «прагматиков» - всемерный учет возможностей и направленность на результат. Они проверяют, что истинно и что ложно, с точки зрения непосредственного личного опыта. Это дает им свободу от последовательности, которая уступает место экспериментированию и инновации. Представители этого стиля мышления превосходят всех в поиске новых способов делать вещи из подручных материалов. Они стремятся подходить к проблемам не спеша, по частям, по одной проблеме за один раз. Они заинтересованы в достижении результата, в отыскании кратчайшего пути и скорейшей окупаемости. «Прагматик» убежден, что в этом мире все и в самом деле происходит постепенно, по частям. Он считает, что мир непредсказуем, не поддается пониманию и контролю в целом. Факты и ценности имеют для «прагматиков» равный вес. Важно то, что «результативно». «Прагматики» быстро схватывают, что люди будут покупать и что продавать. Им хорошо удается поставить себя на место другого человека и почувствовать практические и лич- 
ные последствия предлагаемого решения. Подход к жизни у «прагматиков» носит гибкий и адаптивный характер.

Обобщенные результаты наших исследований позволяют дать уточненную характеристику индивидам, предпочитающим использовать прагматический стиль при решении задач. С точки зрения темперамента у «прагматиков» в большей степени выражена лабильность и уравновешенность нервных процессов, высокий уровень силы процесса возбуждения и торможения. Для них характерны функциональная выносливость, то есть способность выдерживать длительное или кратковременное, но сильное возбуждение, не переходя в состояние охранительного торможения; они легче справляются с ситуациями, где имеют место запреты, воздержание от определенных действий или отсрочка реакции (Подторжнова, 2010). Как отмечалось выше, для «реалистов» характерна обратная ситуация. Таким образом, «реалистам» легче работать в стандартной ситуации, в то время как «прагматики» оставляют место для экспериментирования и инноваций. Несмотря на внешнее сходство эти два стиля существенно отличаются друг от друга. «Реалисты» являются однозначными эмпириками, для них реально только то, что можно потрогать, почувствовать, увидеть, услышать. «прагматики» же не являются принципиальными эмпириками, они опираются на личный опыт, порой интуитивный, тем самым сближаясь с «теоретиками». Но в отличие от «теоретиков» истинность решений «реалисты» проверяют только на личном опыте.

Интересно, что у «прагматиков» была выявлена отрицательная корреляционная связь со шкалой «общая осведомленность». Таким образом, «прагматики», не стремятся существенно расширить запас сведений и знаний в разных областях: географии, биологии, истории и т. д. Вероятно, они в большей степени нацелены на получение конкретных практических знаний в той области, которая является для них значимой.

Обратная ситуация выявлена у «прагматиков» во взаимосвязи с вербальными способностями. У представителей этого стиля отмечаются несколько сниженные относительно остальных стилей вербальные способности. Вероятно, «прагматики», которых больше интересуют конкретные знания и навыки в практически-реализуемой деятельности, уделяют меньше внимания чтению разного рода литературы, не относящейся к выполняемой работе, например, художественной литературы, научной литературы из других областей знаний. Вследствие этого уменьшается тренировка вербального аппарата, снижаются навыки работы с текстом. Вместе с тем, адаптивные и гибкие «прагматики», будут эффективны в работе с рисунками, фотографиями, предметами, со всякого рода наглядно представленным предметным материалом (Подторжнова, 2010).

Для «прагматиков» характерен высокий уровень развития социального интеллекта; они без затруднений предвосхищают последствия поведения, на основе анализа чувств и намерений людей (Авдеева, 2009), и успешно приспосабливаются к изменяющейся ситуации общения. Однако при этом они отвергают компромисс как способ выхода из конфликтной ситуации, таким образом, не желая получать половину возможного выигрыша (Костикова, 2009).

Интересные группы испытуемых выделились при проведении кластерного анализа в исследовании О. Ю. Подторжновой (Подторжнова, 2010). Представите- 
ли первого кластера, назовем их условно «Хранители традиций», предпочитают синтетический стиль мышления, отвергая при этом такие стили как прагматический и реалистический. Им в большей степени присущи такие личностные свойства как замкнутость, застенчивость, подчиненность, высокая нормативность поведения, им не чуждо чувство долга и ответственности. Представители второго кластера - «Преобразователи мира», наоборот, склонны отвергать синтетический стиль, отдавая предпочтение аналитическому, прагматическому и реалистическому стилям. Данному кластеру соответствуют следующие личностные свойства: общительность, доминантность, низкая нормативность поведения.

«Хранителей традиций» можно описать как людей, тяготеющих к теоретическим решениям проблем, которые действуют по заранее намеченному плану, обдумывают каждый свой шаг, мысленно прорабатывают все аспекты своей деятельности. Выделенные для данного кластера личностные особенности, такие как, любовь к идеям, предпочтение работать в одиночестве, направленность на внутренний мир, высокая нормативность поведения находят свое подтверждение в описании А. Ф. Харрисоном и Р. М. Брамсоном синтетического стиля.

Представители «Преобразователей мира», в свою очередь, предпочитают практически ориентированные стили мышления: прагматический и реалистический, отвергая при этом теоретические стили. Все это характеризует их как людей деятельных, способных к реализации любых задач, вместе с тем, не озабоченных планированием и разработкой хода их решения. «Преобразователи» являются хорошими исполнителями планов, разработанных «теоретиками». Эти люди, обладают несколько сниженной нормативностью поведения, могут выделяться стремлением к доминированию, отстаивая свою самостоятельность и проявляя напористость, отдают предпочтения работе с людьми.

Важно отметить то, что для «хранителей традиций» характерен средний возраст 38-40 лет, в то время как средний возраст «преобразователей мира» 28-30 лет, что соответствует особенностям возрастной динамики развития личности в онтогенезе. Период ранней взрослости характеризуется большей социальной активностью, стремлением к преобразованиям, в то время как в период средней взрослости большую ценность приобретает консерватизм и желание сосредоточиться на своем внутреннем мире.

Таким образом, изучение особенностей мышления и на макро, и на мезо и микроуровнях представляется необходимым и сугубо важным для правильного понимания субъекта мышления с точки зрения принятых им решений.

\section{СПИСОК ЛИТЕРАТУРЫ}

Авдеева, Н. А. (2009) Взаимосвязь стилей мышления и социального интеллекта у студентов разных специальностей : дипломная работа, кафедра общей психологии и истории психологии МосГУ. М. (рукопись).

Алексеев, А. А., Громова, Л. А. (1993) Поймите меня правильно или книга о том, как найти свой стиль мышления, эффективно использовать интеллектуальные ресурсы и обрести взаимопонимание с людьми. СПб. : Экономическая школа. $352 \mathrm{c}$. 
Аракелян, К. Ю. (2015) Взаимосвязь стилей мышления с социально-психологическими характеристиками старших подростков : выпускная квалификационная работа специалиста, кафедра общей психологии и истории психологии МосГУ. М. (рукопись).

Ачина, А. (2013) Особенности профессиональной готовности к психодиагностической деятельности студентов-психологов с разными стилями мышления : автореф. дис. ... канд. псих. н. Ростов-на-Дону.

Выготский, Л. С. (1984) Собрание сочинений : в 6 т. М. : Педагогика. Т. 3. История развития высших психических функций. 368 с.

Выготский, Л. С., Лурия, А. Р. (1993) Этюды по истории поведения. М.

Дружинин, В. Н. (1999) Психология общих способностей. 2-е изд. СПб. : Питер Ком, 368 с.

Костикова, М. П. (2009) Особенности стилей мышления и способов разрешения жизненных трудностей у студентов разных специальностей : дипломная работа, кафедра общей психологии и истории психологии МосГУ. М. (рукопись).

Коул, М. (1997) Культурно-историческая психология: наука будущего. М. : Когито-Центр, Издательство «Институт психологии РАН». 432 с.

Лурия, А. Р. (1974) Об историческом развитии познавательных процессов. М. : Наука. 172 с.

Молохина, Г. А. (2010) Возрастные и гендерные особенности стиля мышления студентов : автореф. дисс. ... канд. псих. н. Ростов н/Д.

Подторжнова, О. Ю. (2010) Взаимосвязь стилей мышления и индивидноличностных свойств человека : дипломная работа, кафедра общей психологии и истории психологии МосГУ. М. (рукопись).

Психология и культура (2003) / под ред. Д. Мацумото. СПб. : Питер. 718 с.

Психология развития человека от рождения до смерти (2002) / под ред. А. А. Реана. СПб. : Прайм-Еврознак. 656 с.

Рубинштейн, С. Л. (1998) Основы общей психологии. СПб. : Питер Ком. 688 с.

Тащи, К. В. (2015) Взаимосвязь стилей мышления и пространственно-ориентированных характеристик реактивности человека : выпускная квалификационная работа бакалавра, кафедра общей психологии и истории психологии МосГУ. М. (рукопись).

Харрисон, А., Брамсон, Р. (1998) Думай и постигай. Минск : Попурри, 240 с.

Холодная, М. А. (2004) Когнитивные стили. О природе индивидуального ума. 2-е изд. СПб : Питер. 384 с.

Дата поступления: 20.02.2018 г.

Федоркова Ирина Рудольфовна - кандидат психологических наук, доцент, доцент кафедры общей психологии и истории психологии Московского гуманитарного университета. Адрес: 111395, Россия, г. Москва, ул. Юности, д. 5. Тел.: +7 (499) 374-67-20. Эл. адрес: ira_kislova@mail.ru 
Fedorkova Irina Rudolfovna, Candidate of Psychology, Associate Professor, Associate Professor, Department of General Psychology and the History of Psychology, Moscow University for the Humanities. Postal address: 5, Yunosti St., Moscow, Russian Federation, 111395. Tel.: + 7 (499) 374-67-20. E-mail: ira_kislova@mail.ru

\section{Для цитирования:}

Федоркова И. Р. Изучение проблем мышления на кафедре общей психологии и истории психологии Московского гуманитарного университета [Электронный ресурс] // Научные труды Московского гуманитарного университета. 2018. № 1. URL: http://journals.mosgu. ru/trudy/article/view/680 (дата обращения: дд.мм.гг.). DOI: 10.17805/trudy.2018.1.5 